This item was submitted to Loughborough's Research Repository by the author.

Items in Figshare are protected by copyright, with all rights reserved, unless otherwise indicated.

\title{
A software defined radio comparison of received power with quadrature amplitude modulation and phase modulation schemes with and without a human
}

\section{PLEASE CITE THE PUBLISHED VERSION}

http://dx.doi.org/10.1109/EuCAP.2016.7481832

PUBLISHER

(C) IEEE

VERSION

AM (Accepted Manuscript)

\section{PUBLISHER STATEMENT}

This work is made available according to the conditions of the Creative Commons Attribution-NonCommercialNoDerivatives 4.0 International (CC BY-NC-ND 4.0) licence. Full details of this licence are available at: https://creativecommons.org/licenses/by-nc-nd/4.0/

\section{LICENCE}

CC BY-NC-ND 4.0

\section{REPOSITORY RECORD}

Al-Saffar, Dina A.H., and R.M. Edwards. 2019. "A Software Defined Radio Comparison of Received Power with Quadrature Amplitude Modulation and Phase Modulation Schemes with and Without a Human". figshare. https://hdl.handle.net/2134/23548. 


\title{
A Software Defined Radio Comparison of Received Power with Quadrature Amplitude Modulation and Phase Modulation Schemes with and
} Without a Human

\author{
D. Al-Saffar ${ }^{1,2}$, R. M. Edwards ${ }^{1}$ \\ ${ }^{1} 5$ G Research Center, Loughborough University, UK, R.M.Edwards@lboro.ac.uk \\ ${ }^{2}$ University of Technology, Baghdad, Iraq, D.Al-Saffar@lboro.ac.uk
}

\begin{abstract}
This paper presents the application of softwaredefined radio to the study of received power with and without a human in close proximity to a receiver transmitter pair. Software defined radio is increasingly being used in radio related research and teaching in Universities, Schools and Colleges. For teaching it is typically being used in the classroom in close proximity to users/observers. Because several transceiver sets are needed to compare two or more modulation techniques in conventional radio this presents significant challenges with matching, synchronisation and noise. Two or more separate systems are needed. In contrast with software defined radio simple changes to the ratios of $I$ and $Q$ modulators can execute several modulation methods using the same system. This paper examines the use of a typical software defined radio in close proximity to a user which is typical in a classroom situation. The most suitable of two modulation techniques for use with communication systems close to humans as a function of received power for a typical office environment is presented.
\end{abstract}

Index Terms-SDR; NI-USRP; LabVIEW; Human body communication; Modulation.

\section{INTRODUCTION}

Recently software defined radios (SDRs) have begun to have an impact on the research and teaching of the principles of radio. In 1984 in the USA the Garland Texas Division of ESystems Incorporated (now Raytheon) brought SDR to the attention of several key government agencies using a digital receiver 1984 [1]. The concept was based around the emulation of several distinct physical radios using software on a computer using the minimum of hardware. Later a project named "SpeackEasy" was carried out by U.S. DARPA-Air Force military. The SpeakEasy project emulated more than 10 existing military radios, operating in frequency bands between $2 \mathrm{MHz}$ and $2 \mathrm{GHz}$ [2]. Thus in SDR the signal-processing was implemented on a general-purpose processor, instead of being done in special-purpose hardware [1-3][4]. Therefore SDR could receive and transmit many different radio protocols, as waveforms, based on the software used. Ideally, SDR would be able to create a wireless link at any desirable frequency, with any bandwidth, modulation, transmit power and data rate simply by loading the appropriate software. Many applications have been made using SDR [3]. At its outset there were significant limits of the technology mainly due to difficulties in speed and timing in $\mathrm{A} / \mathrm{D}$ and $\mathrm{D} / \mathrm{A}$ conversation and in particular antenna size as a function of wavelength. However, recent advances in DSP board speed have increased utility and this has meant that software defined radio is beginning to be adopted by educators for the teaching of principles of radio and researchers for the development of new waveforms particularly related to $5 \mathrm{G}$ and signal processing in diversity techniques for antennas. The concept of a software defined antenna has not yet been properly addressed but is beyond the cope of this paper.

Previously there has also been interest in the effect of radio frequency radiation on humans and a great deal of work has been done in relation to specific absorption rate (SAR) [10][11]. However in this paper, we will look rather at the human effect on the waveforms used for 8-PSK and 8-QAM.

For this research simulations were first developed in Matlab for 8-PSK and 8-QAM. These were then coded in LabVIEW and used to drive a software defined radio system. Measurements were compared for a scenario with and without a human perturber at $915 \mathrm{MHz}$ with low power. Results showed that the two modulations had similar received power waveforms without a human in the channel but that the received power was different between the two waveforms with a human in the channel but that the effect of the human on received power was minimal.

\section{PROCEDURE FOR MEASUREMENTS}

Experiments took place in a laboratory of the $5 \mathrm{G}$ Research Center (5GRC) at Loughborough University and were designed to measure any effect of the human body on an NIUSRP link. The laboratory is typical for a university with assortment metal framed furniture, a carpeted metal floor and a ceiling with a large void. Multipath was enhanced using a large board covered in silver foil with height and width beyond the extent of the human perturbed $(1.60 \mathrm{~m} \mathrm{X} 1.50 \mathrm{~m})$. The experimental layout is shown in figure 1 . The system consisted of an NI USRP-2920 used as a transmitter, an NI USRP-2950R used as a receiver and two PCs. These units were sited on wooden tables. LabView was used in the host computers to 
first modulate and then demoduate the two generic waveforms compared. The interface used between the PCs and the USRPs was Shielded Ethernet cable for Tx and MXI Express Interface kit for the Rx. Two Horn 7dBi horn antennas with a gain $7 \mathrm{dBi}$ were driven by the USRPs at $915 \mathrm{MHz}$. These were aligned and directed on boresight. A power meter (ST185SMA CW) was used to confirm the transmitted and received powers. The distance between the transmitter antenna and the receiver antenna was approximately $2.4 \mathrm{~m}$ that can reasonably be considered to be in the far field. The volunteer was an adult male of height $1.74 \mathrm{~m}$ and mass $75 \mathrm{~kg}$, standing on a metal scattering slab. The PCs, USRPS. Ideal constellations for 8QAM and 8-PSK are shown in Figure 1. Careful consideration was given to any possible interference with other legacy equipment and transmit power was kept below $-15 \mathrm{dBm}$. A possible alternative centre frequency of $433.92 \mathrm{MHz}$ may also be practical to demonstrate the systems.

Measurements were taken for two scenarios, one with the volunteer and a metal scattering slab and one without the volunteer with slab in place. Each set of measurements lasted for 100 milliseconds and contained approximately $1 \mathrm{M}$ samples. Data rates for both modulations were identical, with 250k symbols/second.

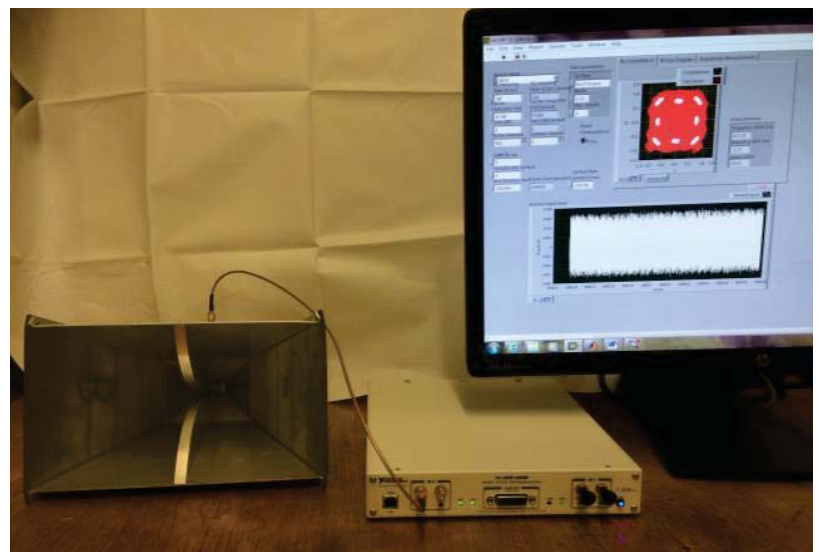

(a)

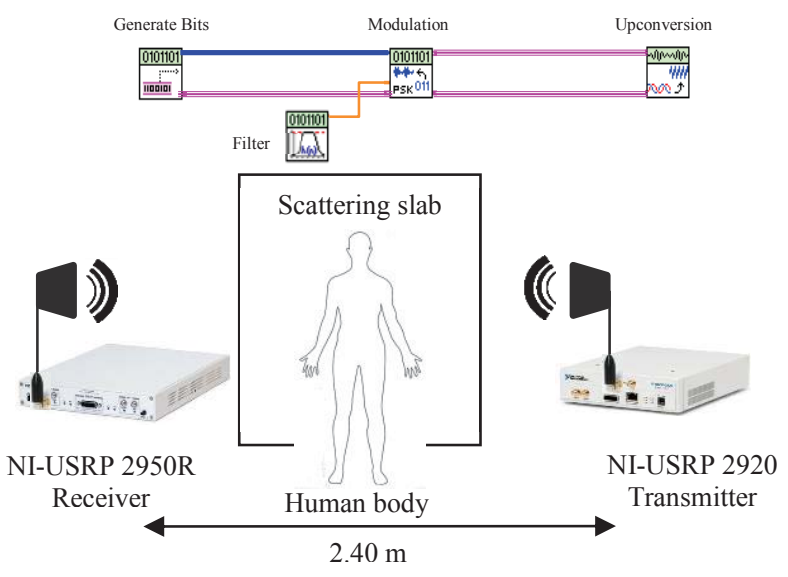

(b)

Fig.1 (a) A picture to the receiver side with the horn antenna, NI-USRP 2950R and 8-QAM demodulation LabView software. (b) The system diagram with two NI-USRP and LabView software platform.
Two common modulation types used over SDR are PSK and QAM. In 8-PSK the phase of a carrier is divided into 8 states, each state expressing designated information.

The processing of the bits and mapping symbols is done in LabVIEW. And then, the I/Q LabVIEW processed signal is passed to the USRP over the gigabit Ethernet or MXI Express Kit. The USRP upconverts the signal to RF according to the USRP configuration set up in LabVIEW. Then the USRP amplifies and transmits the signal over the air[5-7][11].

Also, a quadrature amplitude modulation (QAM) method[11][12], which expresses information with the amplitude of a carrier can increase the number of bits per symbol that can be expressed based on a level which is given to a phase and amplitude of the carrier. 8-QAM can transmit data at high speed in a band limited by radiation of a human body which can be realized.

\section{RESULTS}

Using $d$ in metres between the two horns and $f$ in $\mathrm{GHz}$ as the centre frequency the path loss between the two antennas can be determined from Equn. (1) as .

$$
\text { Path loss }=20 \log _{10}(d)+20 \log _{10}(f)-27.55 \mathrm{dBs}
$$

For a distance of $2.4 \mathrm{~m}$ and a centre frequency of $0.915 \mathrm{GHz}$ this is calculated to be approximately $-20.72 \mathrm{dBs}$ which is $9.28 \mathrm{in} \mathrm{dBm}$. The measured transmit and receive powers for 8-QAM and 8-PSK with an without the volunteer are shown in table I.

TABLE I. TRANSMIT AND RECEIVE POWERS FOR 8-QAM AND 8-PSK WITH AND WITHOUT THE VOLNTEER IN $\mathrm{dBm}$

\begin{tabular}{|c|c|c|}
\hline Modulation Types & With Human & Without Human \\
\hline \multicolumn{3}{|c|}{ Transmitter } \\
\hline 8-QAM & -16.65 & -16.65 \\
\hline 8-PSK & -16.06 & -16.06 \\
\hline \multicolumn{3}{|c|}{ Receiver } \\
\hline 8-QAM & -22.45 & -21.09 \\
\hline
\end{tabular}

The difference of approximately $3 \mathrm{dBm}$ between the result of equation 1 and the measured values can reasonably be assumed to be cabling and antenna mismatch combined with absorption by the volunteer in the human present set. It has previously been established that the RF link does experience additional signal attenuation for due to a human in the channel [8][9][10].

The scenarios, with and without human body measurements and different modulation types are shown in Table 2 in the same environment. 
TABLE II. RESULTS FOR WITH AND WITHOUT HUMAN BODY. RESULTS IN TABLE 1 ARE IN $d B m$ ROUNDED TO 1 DECIMAL PLACE, AT $10^{-3}$ FOR CUMULATIVE DESTRIBUTION FUNCTION. 8-QAM=8-QUADRATURE AMPLITUDE MODULATION, 8-PSK=8- PHASE-SHIFT KEYING

\begin{tabular}{|c|c|c|}
\hline Modulation Types & With Human & Without Human \\
\hline 8-QAM & -86.054 & -84.012 \\
\hline 8-PSK & -84.512 & -82.000 \\
\hline
\end{tabular}

Three representative modulation types results are shown in Figures 2 and 3. The Figures show the Probability Density Function (PDF) and Cumulative Distribution Function (CDF). To obtain the values results of the received signal strength samples were post processed using Matlab.

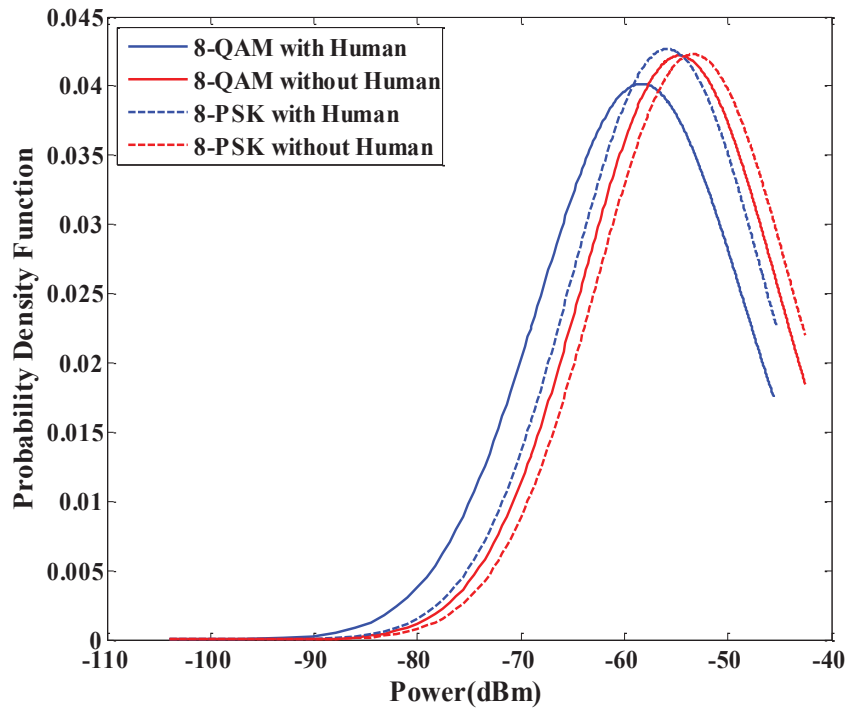

Fig.2 Probability density Function for two types of modulations with and without Human body.

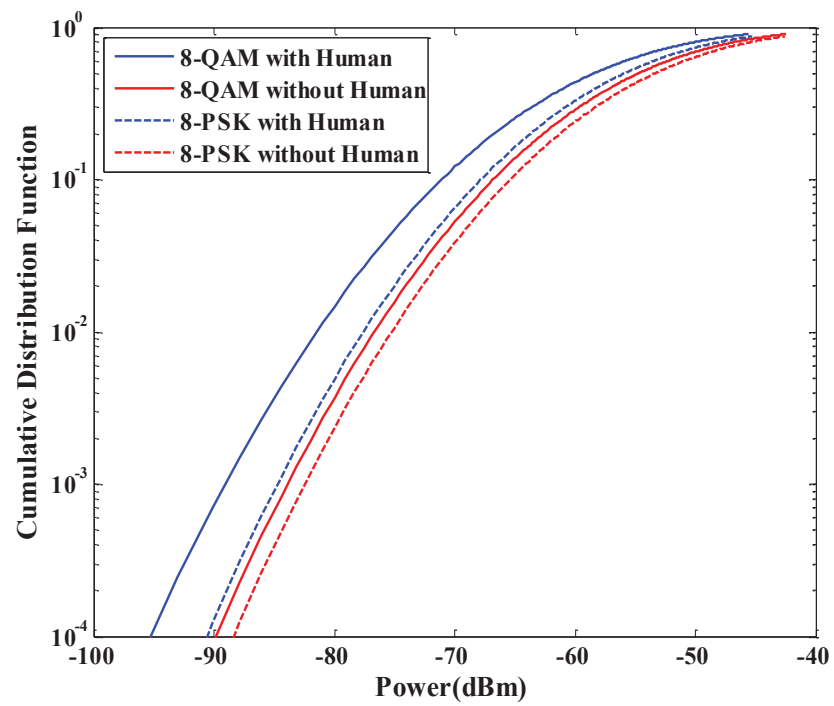

Fig.3 Cumulative Distributions Function for two types of modulations with and without Human body.
With reference to Fig.3. the results for different types of modulations with and without human body in a Lab are presented. The data for these channels is in Table 1, CDF of $99.9 \%$ chosen arbitrarily. The body is at the midpoint of the distance between antennas. The Lab is defently considered as a rich scattering environment.

It can be shown from the figures, the effect of human body on the received signal compared with different types of modulation signals with the same bit rate and sampling time.

The results show a $5 \mathrm{~dB}$ difference for the 8-QAM modulation with and without human body but 8-PSK almost 3 dB. Results were also obtained for QAM and QPSK (not shown here) and these were found to be very similar.

\section{CONCLUSIONS}

In this paper, we have used two modulation techniques to study human interactions in a classroom type environment using software-defined radio channel. We have shown a measurable effect on received power but that the effect although repeatable is not significant in relation to the expected results from experiments typical with SDR. It is therefore reasonable to assume that meaningful results can be obtained for experiments with SDR with set operators in close proximity. It should be noted that a fading simulator may have removed a requirement for the presence of actual humans in the channel. However, the focus of the current paper has been that, an actual human could be present and in close proximity to the chosen Software Defined Radio and allow meaningful result in the receiver side to be obtained for waveforms commonly used in wireless subject lectures and demonstrations. Further it has been established SDR is a useful tool for the comparison of modulation techniques in the presence of human perturbers which is the considered further work for this research.

\section{REFERENCES}

[1] G. D. Space Systems Technology Group, "New Research Lab Leads to Unique Radio Receiver", E-Systems Team magazine, vol. 5, pp. 6-7, 1985.

[2] R. J. Lackey and D.W. Upmal , "Speakeasy: The Military Software Radio" IEEE Communications Magazine, vol. 33,pp.56-61, 1995.

[3] National Instruments. LabVIEW in www.ni.com,

[4] S. Jeon, C. Yu, Y. Suh, J. Moon, and S. Lee, "Analysis of Body Communication Parameters Using Software Radio Platform," pp. 628633,2011 .

[5] T.B. Welch and S. Shearman, "Teaching Software Defined Radio Using the USRP and LabVIEW, "IEEE Int'l. Conf. Acoustics, Speech and Signal Proc.,2012, pp. 2789-92.

[6] M. El-Hajjar, Q. a. Nguyen, R. G. Maunder, and S. X. Ng, "Demonstrating the practical challenges of wireless communications using USRP," IEEE Commun. Mag., vol. 52, no. 5, pp. 194-201, 2014. 
[7] O. Katircioglu, H. Isel, O. Ceylan, F. Taraktas, and H. B. Yagci, "Comparing Ray Tracing, Free Space Path Loss and Logarithmic Distance Path Loss Models in Success of Indoor Localization with RSSI," 19th Telecommun. Forum, pp. 313-316, 2011.

[8] Al-Saffar, D.; Habeeb, E.; Edwards, R.M.; Ojerinde, O.; Alsabbagh, H.M.; Panagamuwa, C.J., "Human effect on on-body selective combining at $2.4 \mathrm{GHz}, "$ in Antennas and Propagation Conference (LAPC), 2014 Loughborough , vol., no., pp.381-384, 10-11 Nov. 2014

[9] Al-Saffar, D.; Edwards, R.M.; Ojerinde, O.; Panagamuwa, C.J.; Seager, R.D., "Human effect on twin antenna On-body for three diversity techniques at $2.4 \mathrm{GHz}, "$ in Antennas and Propagation (EuCAP), 2015 9th European Conference on, vol., no., pp.1-4, 13-17 April 2015.
[10] Al-Saffar, D.; Wen, S.; Edwards, R.M., "User detection at the base station in a GSM 900 mobile phone system," in Antennas \& Propagation Conference (LAPC), 2015 Loughborough , vol., no., pp.14, 2-3 Nov. 2015.

[11] C. R. Rojas, P. Zetterberg, and P. Handel, "Transceiver Inphase/Quadrature Imbalance, Ellipse Fitting, and the Universal Software Radio Peripheral," IEEE Trans.Instrumentation and Measurement, vol. 60, no. 11, 2011, pp. 3629-39.

[12] S. Sergei, K. E. Chichester, W. Sussex,"Modulation and Coding Techniques in Wireless Communication,” Wiley. pp.580-590, 2011. 